\title{
O subimperialismo brasileiro, uma estratégia continuada: entre o regime militar e
}

os anos 2000

The Brazilian sub-imperialism, a continued strategy: between the military regime and the 2000s

Eliton Felipe de Souza ${ }^{1}$

\section{RESUMO}

o presente artigo pretende refletir sobre o papel subimperialista do governo brasileiro iniciado durante o regime militar e que vem se mantendo até os dias de hoje, seja por ataques diretos do regime civil-militar brasileiro a governos democraticamente eleitos, seja pelo apoio dado às empresas nacionais para expandirem o domínio econômico para outras regiões do planeta.

Palavras-chave: Subimperialismo; Regime Militar.

\section{ABSTRACT}

This paper aims to bring considerations about the sub-imperialist role of the Brazilian government that started during the military dictatorship period and that remained until nowadays, either by straight attacks from the Brazilian dictatorship to the democratic elected governments, or by the support provided to the national companies to expand their economic domains to other regions of the world.

Key-words: Sub-imperialism; Military dictatorship.

1 Graduado em História pela Universidade da Região de Joinville - Univille, Mestrando em Sociologia Política pela Universidade Federal de Santa Catarina - UFSC, Florianópolis/SC, Brasil. 


\section{o subimperialismo ${ }^{2}$ do regime militar: o primeiro passo para o avanço das empresas brasileiras}

O Regime civil-militar brasileiro foi muito além de suas fronteiras, ajudando a derrubar governos democraticamente eleitos em países como Uruguai, Chile e Bolívia. Além de ter tido papel fundamental na criação e execução da Operação Condor ${ }^{3}$, que caçava opositores dos regimes ditatoriais sul-americanos, não só na América do Sul, mas, também, na Europa e nos Estados Unidos.

Essa intervenção, porém, não parece ter sido apenas para defender os interesses internos brasileiros ou para assegurar o domínio dos Estados Unidos na economia da região, mas sim para defender a supremacia brasileira frente aos países vizinhos que procuravam meios alternativos ao sistema capitalista vigente naquele momento e davam os primeiros passos em direção a políticas de esquerda. Era de grande importância ao governo brasileiro, portanto, ter a certeza de que esses países não se tornariam uma ameaça à hegemonia brasileira.

Com o desenvolvimento econômico e o crescimento interno do capital financeiro no Brasil, durante os anos 1950, e na "ânsia" de ampliarem os lucros, grandes empresários brasileiros organizaram-se para auxiliar na derrubada do governo do presidente João Goulart, que propunha reformas estruturais na economia do país. Esse processo de apoio à ditadura, tornou-se uma "via de mão dupla": por um lado, os

2 Cunhado por Ruy Mauro Marini, o subimperialismo amarrou várias das ideias de imperialismo dentro da teoria da dependência dando origem a esse novo conceito. Para o autor, a nova divisão internacional do trabalho do pós-guerra fez surgir sub-centros políticos e econômicos como a Índia e o Brasil, que entraram na etapa capitalista dos monopólios e do capital financeiro, mas se mantinham dependentes e subordinados aos países desenvolvidos. Além disso, o governo brasileiro começou a avançar as fronteiras atrás de matérias-primas e fontes de energia, como foi no Tratado de Itaipu com o Paraguai, em um contrato que privilegiou o Brasil e, inclusive, foi danoso para a Argentina que precisou negociar a altura da barragem do Rio Paraná para que pudesse, ela mesma, construir uma hidrelétrica em seu território. "O resultado [do surgimento desses subcentros] foi um reescalonamento, uma hierarquização dos países capitalistas de forma piramidal e, por conseguinte, o surgimento de centros médios de acumulação - que são também potências capitalistas médias - o que nos levou a falar da emergência de um subimperialismo." (MARINI, 1977, p.8). Para Marini o golpe civil-militar brasileiro foi diferente dos anteriores ocorridos no país por criar um esquema econômico-político que consagra a fusão dos interesses da elite militar e do grande capital.

3 A Operação Condor foi criada em 1973-74 como uma rede de cooperação secreta por meio da qual os governos militares da Argentina, Peru, Chile, Bolívia, Paraguai, Uruguai e Brasil se envolveram na apreensão e no assassinato de opositores políticos além de suas fronteiras nacionais" (GILL, 2014). Os governos militares envolvidos na operação tiveram o apoio dos Estados Unidos, por meio do Secretário de Estado Henry Kissinger e coube ao Brasil fornecer a tecnologia de repressão utilizada pela ditadura desde o golpe, em 1964.

Conjuntura Global, Vol.3, n. 3, jul./set., 2014, p. 150-171. 
empresários que auxiliavam na manutenção do governo, do outro, o governo, o qual dava garantias de crescimento econômico aos empresários que expandiam o capital interno, iniciando o avanço sobre outros países.

Um dos ramos privados mais beneficiados pela parceria Ditadura/Empresariado foi o das empreiteiras:

A primeira tentativa de obtenção de obra no exterior pela empresa [Mendes Júnior] ocorreu em 1966, quando a construtora tentou sem sucesso um contrato na Argentina. A primeira obra da firma mineira no exterior foi também a primeira obtida por uma empreiteira brasileira fora do país, a hidrelétrica de Santa Izabel, na Bolívia, iniciada em 1969 (CAMPOS, 2012, p. 110).

A criação da Assembleia Popular, na Bolívia4, em 1971, passou a ameaçar os objetivos da referida empresa brasileira. Era, não só um risco para a hegemonia do sistema capitalista na América Latina, mas, também, um perigo para os interesses econômicos brasileiros. Coube ao governo militar intervir para o retorno da ditadura militar boliviana.

Outra empresa que se aproveitou das ações militares brasileiras, foi a Odebrecht, que iniciou "os primeiros contratos no exterior [...] em 1979, com usinas hidrelétricas no Chile $^{5}$ [...], e uma agressiva política de preços para que a companhia se estabelecesse" (CAMPOS, 2012, p. 118). Além disso, a empresa estendeu as atividades ao Uruguai, assim como a empresa baiana Concic e a gaúcha Maestri, todas durante os anos 1970, após o início da ditadura uruguaia, à qual o governo brasileiro deu auxilio financeiro, logístico e

4 Os militares brasileiros ofereceram aos opositores do governo do general Juan José Torres, dinheiro, armas, aviões e mercenários, e permitiram a instalação de áreas de treinamento perto de Campo Grande (Mato Grosso) e em outros locais próximos da fronteira. Além de dar apoio logístico durante a execução do golpe, com aviões militares que descarregaram fuzis, metralhadoras e munições em Santa Cruz de la Sierra, enquanto tropas do II Exército estacionavam em Mato Grosso, prontas para intervir na Bolívia. Ver mais em Bandeira (2003).

5 Em 1966, quatro anos antes de Salvador Allende ser eleito Presidente do Chile, o marechal Humberto Castello Branco, ditador do Brasil, e seus ministros demonstravam preocupação com os rumos que o Chile estava tomando. Em reunião do Conselho de Segurança, o então chanceler brasileiro, Juracy Magalhães relatou a conversa que teve com o colega chileno, Gabriel Valdez, na qual oferecia auxilio do governo brasileiro caso os militares chilenos quisessem tomar o poder: "se o Governo Frei não conseguir realizar as aspirações do povo chileno. Então - isso eu dizia - seria o caso de ter a possibilidade do hemisfério agir em benefício do Chile [...] as forças vivas da Nação agiriam no Chile, como agiram no Brasil e na Argentina"(SESSÃO DO CONSELHO DE SEGURANÇA NACIONAL, 1966, p.7). No caso do Chile, o Brasil colaborou juntamente com os EUA na preparação e articulação do golpe, como fica evidenciado em documento divulgado pelo governo estadunidense. Ver mais em: National security archive electronic briefing (2013).

Conjuntura Global, Vol.3, n. 3, jul./set., 2014, p. 150-171. 
técnico ${ }^{6}$.

Essa colaboração do governo brasileiro junto às empresas para ajudá-las a expandir suas fronteiras funcionava como uma "via de mão dupla", o interesse existia de ambos os lados:

\begin{abstract}
Ativa colaboradora do regime militar, a Fiesp (Federação das Indústrias do Estado de São Paulo) ajudou, juntamente a outros setores do empresariado paulista, a financiar a repressão e centros de repressão. Um dos maiores exemplos é aquilo do que viria a ser um modelo de centro de tortura para outros lugares do País: a Oban (Operação Bandeirante). Localizado no número 921 da rua Tutóia, onde hoje funciona o $36^{\circ}$ Distrito Policial da Polícia Civil, o local se tornou mais tarde o DOI-Codi (Destacamento de Operações de Informação do Centro de Operações de Defesa Interna), estrutura replicada depois em outras capitais do País (GOMBATA, 2013).
\end{abstract}

Enquanto as empresas brasileiras se internacionalizavam apoiadas pelos militares, no Brasil, eram elas que sustentavam o regime.

\title{
O subimperialismo brasileiro no governo do PT (Partido dos Trabalhadores)
}

Se, durante os anos do regime civil-militar, as empresas brasileiras se expandiram apoiadas pelo governo e, segundo Marini (1992), pelas estratégias estadunidenses na América Latina baseadas na contenção da "ameaça comunista" por meio da Doutrina de Segurança Nacional e do combate aos supostos inimigos internos, abrindo caminho para a ofensiva brasileira na América do Sul e África, esse avanço foi freado nas décadas de 1980 e 1990. De acordo com Bueno; Seabra (2009), isso ocorreu dada a mudança na estratégia imperialista para o continente, fomentando o modelo exportador e abrindo espaço ao capital estrangeiro, e reduzindo a participação do Estado. Além disso, o período coincide com a Crise da Dívida Externa que acentuou a subordinação da América Latina aos programas do Fundo Monetário Internacional. Para os autores, este quadro, nos anos 1980, eliminava as bases políticas objetivas para a continuidade da cooperação antagônica7 ${ }^{7}$ e, portanto, da ação subimperialista brasileira, tendência mantida durante a

$6 \quad$ No Uruguai foram 12 anos de governo militar, entre 1973 e 1985, onde a Doutrina de Segurança Nacional foi aplicada contra os ditos subversivos com o apoio do governo brasileiro que enviou ao Exército do uruguaio centenas de veículos, caminhões e carros, em uma operação da ordem de US\$ 815.000. Ver mais em Bandeira (2003).

7 Para Bueno; Seabra (2009), cooperação antagônica, seria a coexistência de uma ativa e estreita colaboração do governo brasileiro com os EUA para implementar a estratégia geopolítica estadunidense de

Conjuntura Global, Vol.3, n. 3, jul./set., 2014, p. 150-171. 
década de 1990 com a implementação do neoliberalismo e do Consenso de Washington:

Exemplo da educação (escolas privadas), saúde (planos de saúde), previdência (plano de previdência) e segurança (segurança privada). [...] as décadas de 1980 e 1990 trouxeram uma nova configuração no bloco burguês dominante, onde as novas frações não apresentam interesse imediato de conseguir mercados externos, mas sim de se associar com o capital internacional no espaço econômico brasileiro (BUENO; SEABRA. 2009, p. 5).

Já na virada do século, sob a perspectiva de tornar-se o representante das nações emergentes na América Latina, como uma alternativa ao imperialismo estadunidense na região, o Brasil desponta, durante os governos Lula e Dilma, do PT, como o Estado capaz de crescer e ocupar os espaços fragilizados da economia dos países periféricos.

Na década de 2000, [...] se consolida uma fração da burguesia local que retoma o interesse no mercado externo por meio da exportação de capitais, principalmente na forma de investimentos diretos. [...] Surgem políticas públicas voltadas para incentivar a internacionalização, a exemplo da criação de uma linha de crédito específica do Banco Nacional de Desenvolvimento Econômico e Social (BNDES) destinada à implantação de filiais no exterior; regulamentação da atuação de Fundos de Investimentos brasileiros no exterior [...] e a incorporação, dentre os objetivos da criação do Fundo Soberano do Brasil, do estímulo à internacionalização de empresas. Portanto, a década de 2000 recoloca como fator central para os interesses da burguesia na expansão sobre os mercados externos (BUENO; SEABRA. 2009, p. 5).

Esse investimento pesado do governo brasileiro em empresas privadas, possibilitando o crescimento e a expansão dessas, garante ao país um papel de destaque na política internacional. Como 6 $^{\underline{a}}$ maior economia do mundo, o Brasil passou a se destacar nos mais importantes fóruns e organizações internacionais, como o G-20, a Organização Mundial do Comércio (OMC), a UNASUL (União das Nações Sul-americanas) e com a participação na missão de paz da ONU no Haiti. Os investimentos governamentais possibilitaram a ampliação do poder econômico das empresas nacionais além das fronteiras:

Já há em território brasileiro quase mil empresas com presença relevante no exterior - com mais de $10 \%$ do capital de filiais e investimento direto superior a US\$ 10 milhões -, das quais as mais internacionalizadas são: JBS, Marfrig, Brasil Foods, Oderbrecht, Camargo Correa, Gerdau, CSN, Coteminas, Vale, Fibria, Sabó, Ambev, Artecola, Tigre, Embraer, Marcopolo, Petrobras, entre outras (BUGIATO; BERRINGER, 2012, p. 29).

Em 2006, o Brasil, pela primeira vez na história, conseguiu elevar o volume de

estabilização da América Latina com choques pontuais entre os dois países, não como forma de questionar a estratégia dos vizinhos do norte, mas para barganhar vantagens e espaços para o Brasil. 
investimentos diretos no exterior a números superiores aos de investimentos estrangeiros em território nacional, chegando à expressiva marca de US\$32,3 bilhões e alçando o país à $12^{\mathrm{a}}$ posição no ranking dos maiores investidores do mundo, à frente, por exemplo, da Rússia e da Suécia. Os investimentos diretos brasileiros no exterior tiveram enorme e continuo crescimento durante os primeiros anos do século XXI, atingindo, entre 2000 e 2008, valores superiores a sete vezes o volume empregado em toda a década de 1990 (BUGIATO; BERRINGER, 2012).

É espantoso o avanço das empresas brasileiras sobre o mercado estrangeiro, principalmente em países latino-americanos (que correspondem a 38,3\% dos investimentos ${ }^{8}$ ), com o apoio do governo, por meio, sobretudo, do BNDES.

No Uruguai, por exemplo, estima-se que existam cerca de 50 empresas brasileiras. Para se ter uma ideia da importância dessas empresas na economia uruguaia, os frigoríficos brasileiros Marfig, (JBS) Friboi e Minerva controlavam, em 2012, 50\% das exportações de carne ( $2^{\circ}$ principal produto de exportação do país entre janeiro e junho de $2014^{9}$ ), e $40 \%$ de todo o processamento da indústria de carne ${ }^{10}$. Na Argentina, a Petrobras já é a segunda maior empresa de petróleo e gás, enquanto a Camargo Correa comprou a maior empresa produtora de cimento e a (JBS) Friboi as unidades do frigorifico Swift, tornando-se, assim, a maior empresa do ramo no mundo.

No Peru, o controle brasileiro é ainda maior: a Fibria comprou a maior mineradora peruana e possui, hoje, $66 \%$ das jazidas do país, ou seja, mais da metade do minério existente no Peru está nas mãos de uma única empresa brasileira. Além disso, a Gerdau comprou a maior siderúrgica peruana e a Petrobras ocupa a segunda posição entre as maiores produtoras de petróleo.

$8 \quad$ Os investimentos diretos do Brasil em 2011, por região do planeta, foram de 30,9\% na América do Sul; $21,1 \%$ na Europa; $16,8 \%$ na Ásia; $12,6 \%$ na América do Norte; 9,6\% na África; 7,4\% na América Central; e 1,7\% na Oceania (BUGIATO; BERRINGER, 2012)

9 A exportação de carne foi o segundo principal produto de exportação do país entre janeiro e junho de 2014 , com $10,1 \%$ do total. Ficando atrás somente da soja, que foi responsável por $41,0 \%$ das exportações. Ver mais em Uruguay (2014).

10 Os investimentos brasileiros diretos no Uruguai cresceram cerca de $42 \%$ entre 2005 e 2011 , alcançando os U\$S170 milhões ou 7\% do total investido no país nesse período. Ver mais em Gabinete Productivo (2013). 


\section{Algumas considerações}

Os anos 2000 voltaram a aproximar a política externa subimperialista brasileira ao que foi realizado pelos militares, durante os anos da ditadura. 0 período petista veio acompanhado de um forte investimento em políticas econômicas agressivas para além das fronteiras do país, principalmente na América Latina, com uma principal diferença: enquanto o regime civil-militar teve posição muito mais militarizada, de auxilio na derrubada de governos para a manutenção da hegemonia capitalista no Cone Sul, os governos Lula e Dilma optaram por acordos políticos com seus colegas, ao mesmo tempo em que investiram pesado no avanço das empresas privadas sobre os territórios de seus aliados.

O cenário de crise, a partir de 2008, não foi suficiente para frear o avanço das empresas brasileiras no exterior. Resta saber como serão os investimentos do governo brasileiro no novo ciclo político, a partir de 2015. Será de continuidade ou haverá mudanças no fomento às empresas privadas? O Brasil continuará ocupando o espaço de Estado subimperialista, ampliando o poder sobre os vizinhos da América Latina e galgando posições de destaque nas Organizações Internacionais ou haverá novo período de incentivos internos e de interesses neoliberais, com o olhar político-econômico voltado à redução estatal?

\section{Referências bibliográficas}

BANDEIRA, Luiz Alberto Moniz. Brasil e os golpes na Bolívia, Uruguai e Chile: 30 anos depois. Espaço Acadêmico. Maringá, n. 28, set., 2003.

BUENO, F. M.; SEABRA, R. L.. A teoria do subimperialismo brasileiro: notas para uma (re)discussão contemporânea. In: COLÓQUI INTERNACIONAL MARX E ENGELS, 6. 2009, Campinas, Anais... Campinas, 2009.

BUGIATO, Caio Martins. BERRINGER, Tatiana. Um debate sobre o Estado logístico, subimperialismo e imperialismo brasileiro. Em Debate. Florianópolis, n. 7, p. 28-44, jan-jul, 2012. 
CAMPOS, Pedro Henrique Pedreira. A Ditadura dos Empreiteiros: as empresas nacionais de construção pesada, suas formas associativas e o Estado ditatorial brasileiro, 19641985. 2012. 539. Tese (doutorado em História Social) Programa de Pós-Graduação em História Social (PPGHS) da Universidade Federal Fluminense (UFF), Rio de Janeiro, 2012.

GABINETE PRODUCTIVO, República Oriental del Uruguay. Inversiones de Brasil em Uruguay. Disponível em: http://goo.gl/gtA3ku acessado em: 30/10/2014.

GILL, Peter. Alguns aspectos da reforma da inteligência na América Latina. Disponível em: http://goo.gl/jIvHpB; Acessado em: 16/03/2014.

MARINI, R. M.. La acumulación capitalista mundial y el subimperialismo. In: Cuadernos Políticos n ${ }^{\circ}$ 2. México: Ediciones Era, 1977.

MARINI, Ruy Mauro. América Latina: integração e dependência. São Paulo: Brasil Urgente, 1992.

NATIONAL SECURITY ARCHIVE ELECTRONIC BRIEFING. Brazil Conspired with U.S. to Overthrow Allende. Disponével em: http://goo.gl/rm0mPp; Acessado em 10/08/2013.

SESSÃo do CONSElHo DE SEGURANÇA NACIONAL, 39., 1966, Brasília. Arquivo Nacional. Brasília, 2014. Disponível em: http://goo.gl/6Mt7hu acessado em $13 / 03 / 2014$.

URUGUAY XXI. Informe de comercio exterior: exportaciones e importaciones de Uruguay, Junio 2014. Disponível em: http://goo.gl/mJ0imC; Acessado em: 30/10/2014. 